\title{
Effect of dietary cereals on intestinal permeability in experimental enteropathy in rats
}

\author{
J S SANDHU AND D R FRASER
}

From the Dunn Nutritional Laboratory, University of Cambridge and Medical Research Council, Cambridge

SUMMARY A sensitivity to dietary cereal has been reported previously in niacin-deficient rats by measuring a change in the intestinal absorption of radioactively-labelled cellobiotol and mannitol. The possibility that other stimuli could produce this sensitivity, the range of cereals that could induce the permeability change and the nature of the toxic component in cereal have now all been investigated. Treatment with triparanol induces sensitivity in rats to wheat, rye, barley, oats, and maize but not to rice or soybean. These cereals caused a similar response in niacin-deficient rats. Mucosal damage produced by methotrexate or cetrimide, however, did not sensitise the intestinal mucosa to dietary cereals. Gluten, zein, and pepsin/trypsin digests of gluten all induced the permeability defect in triparanol-treated rats. It is concluded that although gross disruption of the mucosal structure may not sensitise rats to cereals, various causes of mucosal cell damage can produce a susceptibility to gluten toxicity that resembles glutensensitivity in man.

Niacin-deficient rats fed a diet containing maize show an increased intestinal absorption of dietary macromolecules. ${ }^{1}$ In the absence of cereal or with rats having adequate niacin status this permeability change is not observed. Hence it is postulated that niacin deficiency sensitises the intestinal mucosal cells to dietary maize which then induces the permeability defect.

To test this hypothesis and to determine whether sensitivity to maize occurs only in niacin deficiency, other procedures for producing experimental enteropathy have been sought. Triparanol, an inhibitor of cholesterol synthesis, can induce malabsorption in $\operatorname{man}^{2}$ and mucosal cell damage in rats. $^{34}$ In one study, this cellular damage was associated with impaired glucose absorption but only when the rats were fed dietary gluten. ${ }^{5}$ In another report, malabsorption of galactose in triparanol-treated rats occurred regardless of the presence of gluten in the diet. ${ }^{6}$

The possibility that triparanol might sensitise the intestinal mucosa' to dietary cereals in a similar manner to niacin deficiency has now been investigated. Mucosal permeability was here monitored by a sensitive, labelled sugar absorption test devised for

Address for correspondence: Dr D R Fraser. Dunn Nutritional Laboratory. Milton Road. Cambridge CB4 1XJ.

Received for publication 2 November 1982 rats. $^{7}$ In this way the specificity of the sensitising agent, the range of cereals able to induce the permeability defect, and the nature of the noxious cereal factor were all explored.

\section{Methods}

ANIMALS AND DIETS

Male Norwegian hooded rats of the Dunn Nutritional Laboratory strain were caged individually, supplied with food and water ad libitum, and exposed to a $12 \mathrm{~h}$ light/12 h dark cycle. A non-cereal synthetic diet based on casein and sucrose with an adequate vitamin content was prepared according to Nakashima et al. ${ }^{8}$ Whole soybean flour and unpolished rice were obtained from local suppliers. Wheat, maize, oats, rye, barley (Buckdon Mill Ltd, Huntingdon, UK) and unpolished rice were coarsely ground in a Junior Laboratory Mill size 5. Each test diet was prepared by mixing $20 \%$ (w/w) of the appropriate ground cereal or soybean flour with the non-cereal synthetic diet. The rats were weaned at body weights of 45-55 g and were initially fed the non-cereal diet for up to 14 days.

Niacin deficiency was induced by feeding for 28 days either a nictotinic acid-deficient diet based on casein (8) or by feeding this diet supplemented with $10 \%(w / w)$ ground wheat, oats, rye, barley, or maize. Control rats for the niacin-deficient animals 
were given single oral doses of $20 \mathrm{mg}$ nicotinamide at weekly intervals.

\section{EXPERIMENTAL PROCEDURE}

Triparanol, [2-(4-chlorophenyl)-1-(4-diethylaminoethoxyphenyl)-1-p-tolylethanol], kindly provided by Dr William L Albrecht of Merrell Co, Cincinnati, Ohio, USA, was stirred continuously with arachis oil at $37^{\circ} \mathrm{C}$ for 24 hours to give a clear solution containing $20 \mathrm{mg}$ triparanol $/ \mathrm{ml}$. This was administered in doses of $0.5 \mathrm{ml}$ daily for 10 days by gastric intubation to rats weighing 60-80 g. Experimental groups of five rats in each were transferred from the non-cereal to the appropriate cereal diets which were fed for three days before starting triparanol treatment and continued for the rest of the experimental period.

Intestinal mucosal damage was also produced with methotrexate and with cetrimide (Sigma Chemical Co, Poole, Dorset, UK) administered as described previously. ${ }^{9}$ The effect of a wheat diet on intestinal permeability was assessed in rats treated with these two pharmacological agents.

Intestinal permeability was determined by measuring the urinary excretion of $\left[{ }^{3} \mathrm{H}\right]$-cellobiotol and $\left[{ }^{14} \mathrm{C}\right]$-mannitol during the five hours after their oral administration. ${ }^{7}\left[1-{ }^{3} \mathrm{H}\right]$-cellobiotol was prepared as previously described ${ }^{7}$ and $D-\left[1-{ }^{14} C\right]$ mannitol was obtained from the Radiochemical Centre, Amersham, Bucks, UK. The dosing solution contained $40 \mathrm{mg}\left[{ }^{3} \mathrm{H}\right]$-cellobiotol $(154$ $\mathrm{mCi} / \mathrm{mol})$ and $10 \mathrm{mg}\left[{ }^{14} \mathrm{C}\right]$-mannitol $(82 \mathrm{mCi} / \mathrm{mol})$ per $\mathrm{ml}$ and was given at a dose rate of $0.1 \mathrm{ml} / 100 \mathrm{~g}$ body weight. Rats were starved overnight and, after dosing, were placed individually in metabolism cages for urine collection. Drinking water was available at all times and food was restored one hour after dosing. Urine was diluted to $5 \mathrm{ml}$ with water, $1 \mathrm{ml}$ was freeze dried to remove any ${ }^{3} \mathrm{H}_{2} \mathrm{O}$, the residue was redissolved in $1 \mathrm{ml}$ water and then mixed with $10 \mathrm{ml}$ Triton X-100/toluene scintillator solution. Radioactivity was measured in two channels of a Packard model 2650 liquid-scintillation spectrometer. The ${ }^{3} \mathrm{H} /{ }^{14} \mathrm{C}$ ratio was calculated and the statistical significance of differences in the values between groups was determined by Student's $t$ test for unpaired samples

\section{CEREAL FRACTIONATION}

The possibility was investigated that wheat gluten or zein (the corresponding gluten fraction from maize) might induce a permeability defect in triparanoltreated rats. Gluten or zein (Sigma Chemical Co) were incorporated into the basic non-cereal diet at concentrations of $10 \%(w / w)$. These diets were fed to rats which then underwent triparanol treatment and intestinal permeability assessment as before. Wheat gluten was also digested with pepsin and trypsin; ${ }^{\circ}$ the hydrolysis products were incorporated into the non-cereal diet and their ability to alter intestinal permeability was tested in rats with triparanol-induced enteropathy.

\section{Results}

Treatment with triparanol caused cessation of growth but the rats appeared otherwise to be in healthy condition. Histologically the intestinal mucosa showed minimal change with some jejunal and ileal villi in section being swollen and club-like and slightly reduced in length. Likewise the niacindeficient rats had retarded growth and the histological appearance of the small intestine resembled that of the triparanol-treated rats.

Intestinal absorption of $\left[{ }^{3} \mathrm{H}\right]$-cellobiotol and $\left[{ }^{14} \mathrm{C}\right]$ mannitol by the control rats was similar for all the cereal and the two non-cereal diets, and there was no significant difference in the $5 \mathrm{~h}$ urinary ${ }^{3} \mathrm{H} /{ }^{14} \mathrm{C}$ ratio between any of them (Table 1 ). Similarly the triparanol-treated rats on the non-cereal casein diet also showed no evidence of altered mucosal permeability. When triparanol treatment was combined with a cereal diet, however, there was an increased excretion of $\left[{ }^{3} \mathrm{H}\right]$-cellobiotol and a

Table 1 Effect of different cereal diets on urinary excretion of orally administered $\left[{ }^{3} \mathrm{H}\right]$-cellobiotol and $\left[{ }^{14} \mathrm{C}\right]$-mannitol in triparanol-treated rats

\begin{tabular}{|c|c|c|c|}
\hline \multirow[b]{2}{*}{ Diet* } & \multicolumn{2}{|c|}{$5 \mathrm{~h}$ urine radioactivity } & \multirow[b]{2}{*}{${ }^{3} \mathrm{H} /{ }^{14} \mathrm{C}$} \\
\hline & ${ }^{3} \mathrm{H}(\mathrm{dpm})$ & ${ }^{14} \mathrm{C}(\mathrm{dpm})$ & \\
\hline \multicolumn{4}{|l|}{ Control rats } \\
\hline Wheat (5) & $57006 \pm 922$ & $49660 \pm 841$ & $1 \cdot 15 \pm 0 \cdot 04$ \\
\hline Rye (5) & $58765 \pm 856$ & $48612 \pm 899$ & $1 \cdot 20 \pm 0.04$ \\
\hline Barley (5) & $55204 \pm 939$ & $48 \quad 120 \pm 975$ & $1 \cdot 15 \pm 0.04$ \\
\hline Oats (5) & $56 \quad 134 \pm 838$ & $45187 \pm 1047$ & $1 \cdot 24 \pm 0.04$ \\
\hline Maize (5) & $55265 \pm 871$ & $48126 \pm 1125$ & $1 \cdot 14 \pm 0 \cdot 05$ \\
\hline Rice (6) & $54010 \pm 1679$ & $41868 \pm 1637$ & $1.29 \pm 0.06$ \\
\hline Soybean (6) & $59713 \pm 1597$ & $51924 \pm 1474$ & $1 \cdot 15 \pm 0.06$ \\
\hline Non-cereal casein (5) & $65825 \pm 791$ & $47940 \pm 1092$ & $1.37 \pm 0.04$ \\
\hline \multicolumn{4}{|c|}{ Triparanol-treated rats } \\
\hline Wheat (5) & $89307 \pm 1349$ & $27215 \pm 841$ & $3.28 \pm 0.05 \dagger$ \\
\hline Rye (5) & $86307 \pm 1101$ & $31500 \pm 796$ & $2.74 \pm 0.04 \dagger$ \\
\hline Barley (5) & $83977 \pm 1266$ & $33610 \pm 860$ & $2.50 \pm 0.05 \dagger$ \\
\hline Oats (5) & $78717 \pm 1601$ & $34217 \pm 812$ & $2.30 \pm 0.05 \dagger$ \\
\hline Maize (5) & $72613 \pm 1727$ & $36135 \pm 765$ & $2.01 \pm 0.05 t$ \\
\hline Rice (6) & $60913 \pm 2095$ & $40613 \pm 1474$ & $1.49 \pm 0.06$ \\
\hline Soybean (6) & $56619 \pm 2007$ & $42814 \pm 1715$ & $1.32 \pm 0.06$ \\
\hline Non-cereal casein (5) & $61163 \pm 1274$ & $44318 \pm 1619$ & $1 \cdot 38 \pm 0 \cdot 05$ \\
\hline
\end{tabular}

* The cereal diets contained $20 \%$ of the appropriate ground cereal mixed with the non-cereal casein diet.

Values are means \pm SEM with the number of rats in each group given in parenthesis.

+ Significantly different from control group $(p<0.001)$. 
decreased excretion of $\left[{ }^{14} \mathrm{C}\right]$-mannitol compared with the respective controls and thus a consequent increase in the ${ }^{3} \mathrm{H} /{ }^{14} \mathrm{C}$ ratio in urine was observed (Table 1). Nevertheless, this response was not uniform for all the cereal diets. The ${ }^{3} \mathrm{H} /{ }^{14} \mathrm{C}$ ratio change was highest with the wheat diet and lowest with the maize diet and the differences between wheat compared with maize, oats, and the noncereal diet were all statistically significant $(p<0.001)$. A notable exception to this cereal effect was found with rice which caused no change in the ${ }^{3} \mathrm{H} /{ }^{14} \mathrm{C}$ excretion ratio in triparanol-treated rats. Similarly, the non-cereal soybean diet had no effect on the absorption of $\left[{ }^{3} \mathrm{H}\right]$-cellobiotol and $\left[{ }^{14} \mathrm{C}\right]-$ mannitol. The specificity of triparanol as the sensitising factor in these experiments was indicated by the absence of change in intestinal permeability in control rats dosed with arachis oil carrier only.

The effect of varying the dose of triparanol on intestinal permeability was investigated in rats fed a maize diet (Table 2). At the lowest dose level of 5 $\mathrm{mg} / \mathrm{kg}$, no change was observed in the ${ }^{3} \mathrm{H} /{ }^{14} \mathrm{C}$ excretion ratio whereas at $50 \mathrm{mg} / \mathrm{kg}$ and $150 \mathrm{mg} / \mathrm{kg}$ this ratio increased significantly. Because the highest dose rate caused a greater change in the ${ }^{3} \mathrm{H} /{ }^{14} \mathrm{C}$ ratio in urine than the rate of $50 \mathrm{mg} / \mathrm{kg}$ used previously to induce enteropathy, ${ }^{56}$ in subsequent experiments triparanol was given at approximately $150 \mathrm{mg} / \mathrm{kg}$.

To characterise further the development of both the triparanol and the cereal effects, the labelled sugar absorption test was performed daily on two sets of rats after initial exposure to these agents. For rats on the $20 \%$ wheat diet, an increase in the ${ }^{3} \mathrm{H} /{ }^{14} \mathrm{C}$ ratio was found 24 hours after the first dose of triparanol (Table 3). The ratio increased on subsequent days reaching a maximum difference from control rats after five days of triparanol treatment. When treatment was stopped the

Table 2 Effect of triparanol dose rate on intestinal permeability in maize-fed rats

\begin{tabular}{|c|c|c|c|}
\hline \multirow{2}{*}{$\begin{array}{l}\text { Triparanol } \\
\text { dose rate } \\
(\mathrm{mg} / \mathrm{kg})^{*}\end{array}$} & \multicolumn{2}{|c|}{5 h urine radioactivity } & \multirow[b]{2}{*}{${ }^{3} \mathrm{H} /{ }^{14} \mathrm{C}$} \\
\hline & ${ }^{3} H(d p m)$ & ${ }^{14} \mathrm{C}(\mathrm{dpm})$ & \\
\hline 0 & $56619 \pm 1411$ & $43220 \pm 1591$ & $1 \cdot 31 \pm 0 \cdot 06$ \\
\hline 5 & $53061 \pm 1521$ & $49136 \pm 1611$ & $1 \cdot 08 \pm 0 \cdot 06$ \\
\hline 50 & $61321 \pm 1986$ & $38602 \pm 1881$ & $1 \cdot 59 \pm 0.07 \dagger$ \\
\hline 150 & $75156 \pm 1623$ & $34613 \pm 1189$ & $2 \cdot 17 \pm 0 \cdot 05 \ddagger$ \\
\hline
\end{tabular}

* Rats were fed a maize diet supplemented with nicotinamide ${ }^{12}$ and were given daily doses of triparanol by gastric intubation. After 10 days of treatment the $\left[{ }^{3} \mathrm{H}\right]$-cellobiotol $/\left[{ }^{14} \mathrm{C}\right]$-mannitol absorption test was performed.

Significantly different from control group: $\dagger(p<0 \cdot 01), \ddagger(p<0 \cdot 001)$. Values for $5 \mathrm{~h}$ urine radioactivity are means \pm SEM with five rats per group.
Table 3 Development of the intestinal permeability defect in wheat-fed rats with time after exposure to triparanol

\begin{tabular}{|c|c|c|c|}
\hline \multirow{2}{*}{$\begin{array}{l}\text { Time (days) } \\
\text { after starting } \\
\text { triparanol* }\end{array}$} & \multicolumn{2}{|c|}{5 h urine radioactivity } & \multirow[b]{2}{*}{${ }^{3} \mathrm{H}^{14} \mathrm{C}$} \\
\hline & ${ }^{3} H(d p m)$ & ${ }^{14} C(d p m)$ & \\
\hline 0 & $55402 \pm 1266$ & $46168 \pm 1436$ & $1 \cdot 20 \pm 0 \cdot 05$ \\
\hline 1 & $72562 \pm 1596$ & $36281 \pm 1477$ & $2 \cdot 00 \pm 0.06 t$ \\
\hline 2 & $74641 \pm 1188$ & $34878 \pm 1270$ & $2 \cdot 14 \pm 0.05 t$ \\
\hline 3 & $77340 \pm 1433$ & $30813 \pm 1699$ & $2.51 \pm 0.06 t$ \\
\hline 4 & $85001 \pm 1637$ & $29311 \pm 1229$ & $2.90 \pm 0.05 \dagger$ \\
\hline 5 & $95618 \pm 1533$ & $28205 \pm 1211$ & $3.39 \pm 0.05+$ \\
\hline 6 & $91161 \pm 1699$ & $28311 \pm 1450$ & $3 \cdot 22 \pm 0.06 t$ \\
\hline 7 & $91178 \pm 1599$ & $29318 \pm 1597$ & $3 \cdot 11 \pm 0 \cdot 06+$ \\
\hline 8 & $94803 \pm 1681$ & $30391 \pm 1501$ & $3 \cdot 12 \pm 0 \cdot 06 \dagger$ \\
\hline
\end{tabular}

* Rats were fed the $20 \%(\mathrm{w} / \mathrm{w})$ wheat diet continuously from four days before starting daily oral administration of $10 \mathrm{mg}$ triparanol per rat. The absorption of $\left[{ }^{3} \mathrm{H}\right]$-cellobiotol and $\left[{ }^{14} \mathrm{C}\right]$-mannitol was measured in groups of six rats every day during triparanol treatment.

Values for $5 \mathrm{~h}$ urine radioactivity are means \pm SEM.

+ Significantly different from the value before giving triparanol $(\mathrm{p}<0 \cdot(001)$.

permeability defect remained apparent for three to four days, after which absorption of the labelled sugars returned to the control level.

A second set of rats on the non-cereal casein diet received triparanol for eight days before being transferred to the $20 \%$ wheat diet. A permeability change was clearly apparent two days after the cereal was introduced and the maximum effect was found after three days on the diet (Table 4).

Although niacin-deficiency was previously shown to sensitise rats to dietary maize, the ability of other cereals to induce a permeability change in this condition had not been investigated. ${ }^{1}$ Niacin

Table 4 Development of the intestinal permeability defect in triparanol-treated rats with time after exposure to wheat diet

\begin{tabular}{clcc}
\hline $\begin{array}{l}\text { Time (days) } \\
\text { after starting } \\
\text { wheat diet }\end{array}$ & \multicolumn{2}{l}{5 h urine radioactivity } & \\
\cline { 2 - 3 } & ${ }^{3} \mathrm{H}(\mathrm{dpm})$ & ${ }^{14} \mathrm{C}(\mathrm{dpm})$ & ${ }^{3} \mathrm{H}^{14} \mathrm{C}$ \\
\hline 0 & $62361 \pm 1682$ & $42130 \pm 901$ & $1 \cdot 48 \pm 0 \cdot 05$ \\
1 & $67384 \pm 1295$ & $40110 \pm 821$ & $1 \cdot 68 \pm 0 \cdot 04$ \\
2 & $73715 \pm 1640$ & $36135 \pm 760$ & $2 \cdot 04 \pm 0 \cdot 05 \dagger$ \\
3 & $93703 \pm 1611$ & $30081 \pm 1011$ & $3 \cdot 12 \pm 0 \cdot 05+$ \\
\hline
\end{tabular}

${ }^{*}$ Rats were fed non-cereal casein diet and given daily oral doses of $10 \mathrm{mg}$ triparanol for eight days before changing to $20 \%$ (w/w) wheat diet. Triparanol dosing then continued and the $\left[{ }^{3} \mathrm{H}\right]-$ cellobiotol/ $\left[{ }^{14} \mathrm{C}\right]$-mannitol absorption test was performed daily on groups of six rats.

Values for $5 \mathrm{~h}$ urine radioactivity are means \pm SEM.

+ Significantly different from value before feeding wheat diet $(\mathrm{p}<0.001)$. 
deficiency was produced by feeding a casein-based diet deficient in niacin and tryptophan ${ }^{8}$ and containing $10 \%(\mathrm{w} / \mathrm{w})$ added ground cereal. All these diets caused cessation of growth by 28 days when compared with nicotinamide-dosed controls. ${ }^{1}$ On assessing the absorption of $\left[{ }^{3} \mathrm{H}\right]$-cellobiotol and $\left[{ }^{14} \mathrm{C}\right]$-mannitol all the cereals tested were found to induce an increase in the ${ }^{3} \mathrm{H} /{ }^{14} \mathrm{C}$ excretion ratio in urine of niacin-deficient rats (Table 5). As with the triparanol-treated rats the wheat diet produced the greatest increase and the maize diet the smallest increase in the ${ }^{3} \mathrm{H} /{ }^{14} \mathrm{C}$ ratio. Nicotinamide-treated control rats showed no effect of any of the cereals on the absorption of the labelled sugars.

Intestinal permeability defects have been reported in rats after subcutaneous injection of the cytostatic drug methotrexate, and oral administration of the detergent centrimide. ${ }^{9}$ Gross changes in the absorption of the labelled sugars were also found after these treatments, ${ }^{7}$ but the possible influence of dietary cereal has not yet been described. In the present study methotrexate-treated rats showed decreased absorption of both $\left[{ }^{3} \mathrm{H}\right]$-cellobiotol and $\left[{ }^{14} \mathrm{C}\right]$-mannitol compared with non-treated controls, however, this effect was seen in rats on both the wheat diet and the non-cereal diet (Table 6). Treatment with cetrimide, on the other hand, enhanced the absorption of both sugars but again the effect was equally apparent on both the cereal

Table 5 Effect of different cereal diets on urinary excretion of orally administered $\left[{ }^{3} \mathrm{H}\right]$-cellobiotol and $\left[{ }^{14} \mathrm{C}\right]$-mannitol in niacin-deficient rats

\begin{tabular}{|c|c|c|c|}
\hline \multirow[b]{2}{*}{ Diet* $^{*}$} & \multicolumn{2}{|c|}{5 h urine radioactivity } & \multirow[b]{2}{*}{${ }^{3} \mathrm{H} /{ }^{14} \mathrm{C}$} \\
\hline & ${ }^{3} H(d p m)$ & ${ }^{14} C(d p m)$ & \\
\hline \multicolumn{4}{|c|}{ Niacin-supplemented rats } \\
\hline Wheat & $59600 \pm 1601$ & $52280 \pm 1415$ & $1 \cdot 14 \pm 0 \cdot 06$ \\
\hline Rye & $61731 \pm 1839$ & $54629 \pm 1301$ & $1 \cdot 13 \pm 0 \cdot 06$ \\
\hline Barley & $58613 \pm 1785$ & $48844 \pm 1445$ & $1 \cdot 20 \pm 0 \cdot 06$ \\
\hline Oats & $60117 \pm 1615$ & $54159 \pm 1201$ & $1 \cdot 11 \pm 0 \cdot 05$ \\
\hline Maize & $55116 \pm 1574$ & $48347 \pm 1437$ & $1 \cdot 14 \pm 0 \cdot 06$ \\
\hline Non-cereal casein & $60316 \pm 1704$ & $48252 \pm 1481$ & $1 \cdot 25 \pm 0 \cdot 06$ \\
\hline \multicolumn{4}{|l|}{ Niacin-deficient rats } \\
\hline Wheat & $80910 \pm 1409$ & $29010 \pm 864$ & $2 \cdot 79 \pm 0.05 \dagger$ \\
\hline Rye & $78360 \pm 1705$ & $30908 \pm 1161$ & $2.54 \pm 0.05 \dagger$ \\
\hline Barley & $74380 \pm 1831$ & $32022 \pm 1463$ & $2 \cdot 32 \pm 0.06 t$ \\
\hline Oats & $70909 \pm 1707$ & $33454 \pm 900$ & $2 \cdot 12 \pm 0.05 t$ \\
\hline Maize & $67721 \pm 1811$ & $35312 \pm 1308$ & $1.92 \pm 0.06+$ \\
\hline Non-cereal casein & $59163 \pm 1616$ & $42259 \pm 957$ & $1 \cdot 40 \pm 0.05$ \\
\hline
\end{tabular}

* The non-cereal niacin-deficient diet (8) was mixed with $10 \%$ $(w / w)$ of the various ground cereals. Niacin deficiency was established by 28 days at which time the $\left[{ }^{3} \mathrm{H}\right]$-cellobiotol $/\left[{ }^{14} \mathrm{C}\right]$ mannitol absorption test was performed.

Values for $5 \mathrm{~h}$ urine radioactivity are means \pm SEM for groups of five rats.

† Significantly different from control groups $(\mathrm{p}<0.001)$.
Table 6 Effect of dietary wheat on intestinal permeability in methotrexate-treated and cetrimide-treated rats

\begin{tabular}{|c|c|c|c|}
\hline \multirow[b]{2}{*}{ Diets } & \multicolumn{2}{|c|}{5 h urine radioactivity } & \multirow[b]{2}{*}{${ }^{3} \mathrm{H}^{14} \mathrm{C}$} \\
\hline & ${ }^{3} H(d p m)$ & ${ }^{14} C(d p m)$ & \\
\hline $\begin{array}{l}\text { Control wheat diet* } \\
\text { Methotrexate-treated } t\end{array}$ & $60101 \pm 2241$ & $43869 \pm 1834$ & $1 \cdot 37 \pm 0 \cdot 07$ \\
\hline $\begin{array}{l}\text { Wheat diet }{ }^{*} \\
\text { Non-cereal casein dict }\end{array}$ & $\begin{array}{r}36915 \pm 1839 \$ \\
t 40128 \pm 1839 \$\end{array}$ & $\begin{array}{l}22623 \pm 1346 \$ \\
25749 \pm 1393 \$\end{array}$ & $\begin{array}{l}1 \cdot 63 \pm 0 \cdot 06 \\
1 \cdot 55 \pm 0 \cdot 06\end{array}$ \\
\hline Cetrimide-treated $\ddagger$ & & & \\
\hline $\begin{array}{l}\text { Wheat diet }{ }^{*} \\
\text { Non-cereal casein diet }\end{array}$ & $\begin{array}{r}94200 \pm 2688 \$ \\
t 89388 \pm 1393 \$\end{array}$ & $\begin{array}{l}64081 \pm 1789 \$ \\
65890 \pm 1392 \$\end{array}$ & $\begin{array}{l}1 \cdot 47 \pm 0 \cdot(07 \\
1 \cdot 36 \pm 0 \cdot 05\end{array}$ \\
\hline
\end{tabular}

Values for $5 \mathrm{~h}$ urine radioactivity are means \pm SEM for groups of five rats.

* $20 \%$ ground wheat was mixed with the non-cereal casein dict. † Methotrexate was injected subcutaneously at $12 \mathrm{mg} / \mathrm{kg}$ body wt, and the $\left[{ }^{3} \mathrm{H}\right]$-cellobiotol $/\left[{ }^{14} \mathrm{C}\right]$-mannitol absorption test was performed $72 \mathrm{~h}$ later.

$\ddagger$ The labelled sugar dosing solution here contained $\left.4 \mathrm{mg} \mid{ }^{3} \mathrm{H}\right]$ -

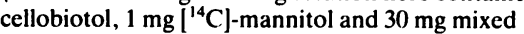

alkyltrimethylammonium bromide (cetrimide BP) in $0.5 \mathrm{ml}$ water. This was given orally in the absorption test at $0.5 \mathrm{ml} / 100 \mathrm{~g}$ body wt. $\S$ Significantly different from control wheat diet $(p<0 \cdot 001)$.

and non-cereal diets (Table 6). Hence, these two types of intestinal damage do not appear to sensitise the rat to dietary cereal nor do they discriminate in the absorption of the labelled sugars.

It was notable that the relative toxicity of the various cereals in triparanol-treated rats closely resembled that in humans with coeliac disease. Therefore, the possibility that gluten might be a toxic component of the cereals in the sensitised rats was investigated. Wheat gluten and maize gluten (zein) were fed to rats receiving triparanol and the labelled sugar permeability test was performed. Both cereal proteins increased the ${ }^{3} \mathrm{H} /{ }^{14} \mathrm{C}$ ratio in urine of triparanol-treated rats (Table 7). Like the relative potencies of whole wheat and whole maize, however, the effect of wheat gluten was much greater than that of zein. Wheat gluten was also hydrolysed enzymically first with pepsin and then with trypsin ${ }^{10}$ to yield an insoluble residue at $\mathrm{pH} 4.5$ (fraction VI) and a water-soluble supernatant (fraction III). Both preparations were freeze-dried, incorporated as $10 \%$ mixtures with the non-cereal diet and then fed to rats. With triparanol treatment fraction III caused a pronounced increase in the ${ }^{3} \mathrm{H} /{ }^{14} \mathrm{C}$ ratio in urine whereas fraction VI had no effect detectable by the permeability assay (Table 7). As with the whole cereals, gluten and the gluten fractions had no effect on intestinal permeability in rats in the absence of triparanol treatment.

The toxicity of the gluten fractions in triparanoltreated rats was comparable to their effect reported in human coeliac disease. ${ }^{10}$ In a clinical test for 
Table 7 Induction of the intestinal permeability defect by dietary gluten and partially digested gluten in triparanoltreated rats

\begin{tabular}{|c|c|c|c|}
\hline \multirow[b]{2}{*}{ Diet $^{*}$} & \multicolumn{2}{|c|}{$5 \mathrm{~h}$ urine radioactivity } & \multirow[b]{2}{*}{${ }^{3} \mathrm{H}^{\prime+} \mathrm{C}$} \\
\hline & ${ }^{3} \mathrm{H}(\mathrm{dpm})$ & ${ }^{14} C(d p m)$ & \\
\hline \multicolumn{4}{|l|}{ Control rats } \\
\hline Ground wheat & $55916 \pm 1761$ & $47143 \pm 1.395$ & $1 \cdot 19 \pm 0 .(1) 6$ \\
\hline Gluten & $54620 \pm 1034$ & $49047 \pm 11,32$ & $1 \cdot 11 \pm 0.015$ \\
\hline Gluten fraction III & $54062 \pm 901$ & $49811 \pm 991$ & $1 \cdot(19 \pm 0(1) \cdot(1)$ \\
\hline Gluten fraction $\mathrm{Vl}$ & $57316 \pm 1861$ & $47143 \pm 966$ & $1 \cdot 22 \pm(1 \cdot(15$ \\
\hline Zcin & $57136 \pm 1401$ & $49618 \pm 922$ & $1 \cdot 1.5 \pm(0 \cdot() 5$ \\
\hline Non-cercal cascin & $65815 \pm 1889$ & $48470 \pm 1171$ & $1 \cdot 36 \pm 0 \cdot(06$ \\
\hline \multicolumn{4}{|c|}{ Triparanol-treated rats } \\
\hline Ground wheat & $97340 \pm 1842$ & $32811 \pm 945$ & $2.97 \pm(0.05 t$ \\
\hline Gluten & $122000 \pm 1718$ & $29615 \pm 1216$ & $4 \cdot 12 \pm 0.06 t$ \\
\hline Gluten fraction III & $136513 \pm 2913$ & $27615 \pm 741$ & $4.94 \pm 0 \cdot(06+$ \\
\hline Gluten fraction VI & $56916 \pm 1034$ & $471+3 \pm 1101$ & $1 \cdot 21 \pm 0 .(05$ \\
\hline Zein & $88615 \pm 1718$ & $36+13 \pm 1.368$ & $2 \cdot 27 \pm 0 \cdot 06$ \\
\hline Non-cereal cascin & $62258 \pm 1145$ & $45817 \pm 1016$ & $1 \cdot 36 \pm 0 \cdot 05$ \\
\hline
\end{tabular}

* The diets were prepared by mixing $20 \%(w / w)$ ground wheat or $10 \%(w / w)$ cach of gluten. gluten fraction III. gluten fraction VI or zein with the non-cereal cascin diet. The dicts were fed and triparanol-treatment was continued for 10 days at which time the $\left[{ }^{3} \mathrm{H}\right]$-cellobiotol/ $\left[{ }^{1+} \mathrm{C}\right]$-mannitol absorption test was performed. Values are means \pm SEM for groups of five rats.

+ Significantly different from respective control group ( $\mathrm{p}<0 \cdot 001)$.

gluten intolerance it was found that fraction VI was inactive but fraction III retained the toxic properties of untreated gluten.

\section{Discussion}

In this study two quite distinct stimuli were found to sensitise the intestinal mucosa of rats to dietary cereal with a resulting change in mucosal permeability. Both niacin deficiency and the drug triparanol produced this response to wheat, rye, barley, oats, and maize. For both of these sensitising conditions the effect was greatest with wheat and least with maize. As all the cereals were fed in equal concentrations it was concluded that some specific component, varying in amount or potency, in the ground cereal was an active inducer of the permeability defect.

The similarity of this cereal effect in rats to gluten-sensitive enteropathy in man implied that a glutelin or prolamine protein might be the toxic factor. Furthermore, rice does not induce the permeability change in rats and is known to contain only traces $(0.1 \%)$ of prolamine protein. The other cereals, in comparison, contain $4-5 \%$ of the total dry weight as prolamine protein. ${ }^{11}$ Thus the finding that gluten, zein and enzymically-degraded gluten were all effective inducers of permeability in sensitised rats points to the gluten-type proteins as mediators of the cereal effect.

Like gluten-sensitivity in coeliac disease, however, the mechanism of the gluten action in rats is unknown. The observation that the permeability change takes $24-48$ hours after exposure to wheat before becoming apparent indicates an induced modification of cell function rather than a direct change to permeability channels in the sensitised cells. Similarly, the finding that treatment with triparanol is needed for up to five days to produce maximum sensitivity suggests a gradual increase in the population of sensitised cells, with cell renewal up the villi. Although the nature of the glutenmucosal cell interaction is quite undefined, this example of gluten sensitivity in rats provides an opportunity for further experimental comparison with the similar mucosal dysfunction in man.

It must be emphasised, however, that although gluten has been shown in this study to have a noxious effect on susceptible intestinal mucosa in rats, an effect which is analogous to gluten-sensitive enteropathy in man, the severity and extent of the pathology which results is by no means comparable in the two species. In man, gluten sensitivity leads to villous atrophy, crypt hyperplasia, infiltration of the mucosa with lymphocytes and clinical signs of nutrient malabsorption. In the rat none of this histopathology is readily apparent. Thus the permeability change in the rat mucosa represents a simple consequence of gluten interaction with a sensitised mucosa. Because of this, gluten sensitivity in the rat is an animal model which could help identify a primary mechanism for enterocyte susceptibility to gluten, irrespective of species.

In previous studies of triparanol-induced enteropathy in rats one report described a sensitivity to gluten ${ }^{5}$ whereas another was unable to find this effect. ${ }^{6}$ The ready demonstration of gluten sensitivity in the present investigation therefore deserves comment. One point of difference between this and earlier studies was the use here of small $(60-80 \mathrm{~g})$ Norwegian hooded rats instead of large $280-350 \mathrm{~g}$ ) Wistar rats. Although hooded rats of 230-280 g gave a clear permeability change in response to triparanol and the maize diet (results not shown), it is possible that this strain was more sensitive to the intestinal toxicity of triparanol. Nevertheless, in a small scale comparative trial of the effects of triparanol, the Wistar rats became noticeably more debilitated than the hooded rats. Moreover, while the dose rate of 50 $\mathrm{mg}$ triparanol $/ \mathrm{kg}$ body weight per day, used in the previous studies was able to sensitise the intestine of the hooded rats, the standard procedure in these experiments used the more effective dose rate of 150 $\mathrm{mg} / \mathrm{kg}$ body weight per day. Thus the hooded rats appeared to be more tolerant than the Wistar rats to 
the general toxicity of triparanol and the use of the higher dose may have enabled the gluten sensitivity to be more readily revealed. Probably the most important factor in the clear cut demonstration of the permeability response to gluten, however, was the sensitivity and repeatability of the labelled sugar absorption test. $^{7}$

Because niacin deficiency and triparanol both have independent and different biochemical effects on cell function yet both sensitise the intestinal mucosa to gluten, some response, possibily in the microvilli, appears to be common to the two stimuli. In contrast, in cytostatic villous atrophy caused by methotrexate and with detergent disruption of the epithelial cell layer by cetrimide, there is neither sensitivity to cereals nor a change in the relative absorption of $\left[{ }^{3} \mathrm{H}\right]$-cellobiotol and $\left[{ }^{14} \mathrm{C}\right]$-mannitol. It is therefore concluded that actual cellular dysfunction rather than gross disruption of the mucosal architecture is necessary for gluten sensitivity to develop. A variety of stimuli may eventually be found to modify the function of the enterocytes with the single consequence of inducing susceptibility to gluten toxicity.

\section{References}

1 Sandhu JS, Fraser DR. The metabolic origin of trigonelline in the rat. Biochem J 1981; 200: 495-500.

2 McPherson JR, Summerskill WJ. An acute malabsorp- tion syndrome with reversible mucosal atrophy. Gastroenterology 1963; 44: 900-4.

3 McPherson JR, Shorter RG. Intestinal lesions associated with triparanol. A clinical and experimental study. Am J Dig Dis 1965; 10: 1024-33.

4 Riecken EO, Rosenbaum R, Bloch R, Menge H, Ritt E, Asslan M, Dölle W. Tierexperimentelle Untersuchungen zur Frage der Spezifität der Dunndarmschleimhautveränderung bei der einheimischen Sprue. Klin Wochenschr 1969; 47: 202-14.

5 Bloch R, Menge H, Martini GA, Riecken EO. Effect of gluten on glucose absorption from the small intestine in experimentally induced malabsorption in rats. Digestion 1972; 7: 139-46.

6 Soulé J-C, Neale G, Peters TJ. Functional and biochemical evidence of damage to enterocytes induced by triparanol: role of lysosomes and the effect of a gluten-free diet. Clin Sci Mol Med 1976; 51: 19-25.

7 Sandhu JS, Fraser DR. Assessment of intestinal permeability in the experimental rat with $\left[{ }^{3} \mathrm{H}\right]$ cellobiotol and $\left[{ }^{14} \mathrm{C}\right]-$ mannitol. Clin Sci 1982; 63: 311-316.

8 Nakashima Y, Sanada H, Utsuki Y, Kawada S. Effect of nicotinic acid on catecholamine synthesis in rat brain. J Nutr Sci Vitaminol 1978; 24: 67-76.

9 Cobden I, Rothwell J, Axon ATR. Passive permeability in experimental intestinal damage in rats. Clin Sci 1981; 60: 115-8.

10 Frazer AC, Fletcher RF, Ross CAC, Shaw B, Sammons HC, Schneider R. Gluten-induced enteropathy. The effect of partially digested gluten. Lancet 1959; 2: 252-5.

11 Bonner J. Plant Biochemistry 1st ed. New York: Academic Press, 1950: 253. 